\title{
Education! Training! Recruitment! Comments on the Cambridge Conference

\author{
From a SPecial Correspondent
}

About 200 people gathered at King's College, Cambridge. 26-28 March, for a joint Conference on Education and Training in Psychiatry and aspects of Recruitment, sponsored by the Associations of University Teachers of Psychiatry, and of Psychiatrists in Training (AUTP and APIT) and the Royal College of Psychiatrists-a follow-on to the famous Oxford conference of 1970 (Russell and Walton). The sun shone, the daffodils glowed against the smooth green lawns, the Cam drifted beneath weeping willows, and everyone was in high spirits for the first discussion.

Rather surprisingly the theme of the evening seemed to be why people don't like psychiatrists, with a debate on whether students of medicine should be selected for psychologicalmindedness at 18 . Since no one had discussed what jobs psychiatrists are actually doing, and there was no solid evidence on the special characteristics of present successful trainees, it was impossible to take seriously these proposals for excluding people from the profession. An American paper which advised against accepting as trainees those who expressed Communist beliefs, or who slept with the nurses in hospital. was greeted with hilarity, and there was also reference to the 'Hippocratic Oath' mentioned in the conference documents. In the end there was agreement that the maturity which comes with age and varied experience had produced good psychiatrists in the past and might continue to do so.

That first evening displayed many of the unresolved dichotomies which are so confusing if one does not start from a base in actuality and political reality. Were we trying to recruit to the psychological viewpoint the 142 medical students who go into general practice, etc., or the 8 who might come into psychiatry? Is the prime function of the psychiatrist to be a caring professional or a kind of diagnostician? Should medical school teaching be based on a liaison psychiatric service or on experience or psychosis and psychogeriatrics?

The working style of the Conference became evident the next day. Under the guidance of a steering committee, 14 working parties had laboured over 18 months on such themes as general professional training (continued experience after full medical registration), higher training, recruitment for research, training settings, and manpower considerations. Their reports, complete with recommendations. had been boiled down to make a 200-page book cveryone was supposed to have read and digested before getting to Cambridge. Three eighty-minute sessions were set aside so that participants could split into four study groups and discuss the 14 reports: a reporter from each group on each occasion then summarized the discussion at a plenary session of the whole Conference. With so many reports to receive. there was little time for further discussion, and it was not clear how the original recommendations put forward in the book were going to be modified when, as quite often happened. the study group threw them out. There is, of course. to be a full Conference report, and another conference after that.

Participants awoke on Sunday morning to a cold fenland fog which reflected their somewhat confused and battered spirits after so much argument over so many topics on the Saturday. Yet, now was to come the most important session of all, which could have shaped the whole two days of debate if the programme had not been planned backwards. It was on the future of manpower and of the psychiatric services, an urgent practical matter if the Short report on reduction of registrars and increase in consultants is to be applied in psychiatry as elsewhere in medicine. This is bound to mean some hospital consultants will have no junior staff, no one they are obliged to train, as at present. This therefore will open the way to a reorganization of teaching, and the ('ollege may revise its Approval scheme so that henceforth approval is given to individual consultants in particular settings. and not simply to hospitals. The consultant who teaches poorly or does not want to teach should therefore be relieved of a burden, and the others will be more easily grouped in relation to academic centres. But without the stimulus of juniors the non-teaching consultants will require much provision for further education, and obviously there will be new problems of morale and recruitment.

The programme of the meeting was too rich. Teaching by videotape or audiotape, by experienced interviewer on closed-circuit television, the importance of enthusiasm in the teacher, the value of specific teaching targets (more than a detailed syllabus) in higher training... these were all important topics, but not for this occasion. As this is neither a full nor a balanced report, I will give my own opinion. I think the Conference should have started with consideration of the jobs (note the plural) psychiatrists actually do, either because their patients or the community expect them to or because they find themselves doing them.

Then one could consider which parts of the work are obligatory in one way or another, and how this is likely to change in the next 15 years because of social change, scientific advance, or change in national beliefs. When we know what we are training to do, and see our targets, we can sharpen our aims, develop our aids, select the clearestsighted recruits. The targets would determine relevance in Conference discussions, and relevance was what was some- 
times lacking this weekend. Psychiatric syllabuses and teaching, and of course the Membership examination, are all orientated towards diagnosis. The formulation, explicit or implicit, is always a prerequisite to any choice of treatment, plan of management, or prediction of who will do well. Diagnostic formulation is the number one way in which psychiatrists, by target, by training and experience, differ from nurses, social workers and other so-called caring professionals, and the curious thing is the conference barely mentioned it.

To be critical does not mean one is ungrateful for all the hard work which goes into mounting such a meeting. Part of its value lies in the stimulatory effect of the pre-Conference working parties, part in the opportunities for informal social contacts in beautiful and unusual surroundings, with a very high standard of eating and drinking. And of course this Conference is not the finish, but just another step towards adapting practice to need.

\title{
Report on the Conference on Tasks and Problems for Peripatetic Trainees in Psychotherapy
}

\author{
JoHN SkLaR, Senior Registrar in Psychotherapy, The Tavistock Clinic
}

The one-day conference, organized by the Psychotherapy Advisory Sub-Committee of the Joint Committee in Higher Psychiatric Training took place on 8 October 1981 under the chairmanship of $\mathrm{Dr} \mathrm{H}$. Wolff, at the Institute of Psychoanalysis.

The Conference took off with Dr Tom Main's account of his group of doctors practising in sexual clinics in Newcastle which he supervises weekly by telephone. He insisted that psychotherapeutic skills cannot be divorced from the setting in which they are used.

Dr Malcolm Pines gave an account of a two-year course by the Institute of Group Analysis in Denmark. Though initially aimed at teaching supervision, it had become a training in basic psychodynamic principles.

Dr Colin James followed on by talking about his five-year training course in group psychotherapy, also in Denmark. He felt that the adaptation to the setting must in no way interfere with the task of teaching psychoanalytic theory and technique.

Dr John Cobb brought the conference back to Britain by describing his peripatetic training in the South West Thames Region. Covering 200,000 miles in two years, he endeavours to teach 'the psychotherapies' using a variety of techniques. He enounters many problems, highlighted by the basic lack of interpersonal skills in our medical profession.

Dr John Evans was the last trainer to speak. He took the view that consultants in psychotherapy should have an 'indepth training' as provided by the Scottish Institute of Human Relations or the Institute of Psycho-analysis.

The participants were then divided into four groups each including a member of the Psychotherapy Advisory SubCommittee.

In the afternoon four trainees were invited to speak. The first. Dr P. Whewell, described his life as a senior registrar in Newcastle training at the Scottish Institute of Human
Relations in Edinburgh, and the effort involved.

Dr Klar, from York, followed with an enthusiastic account of his training in behaviour therapy at the Institute of Psychiatry.

Dr Somekh, a senior registrar in general psychiatry at the Maudsley Hospital and a trainee at the Institute of Psychoanalysis. described the polarization in his hospital between general psychiatrists and psychotherapists and commented on the negative attitudes towards psychoanalytic training which seemed to be held by some senior staff at his hospital, despite the College's approval of the Institute training as a valuable component of the senior registrar's training in psychotherapy.

Dr Jane Price from Nottingham was the only trainee to speak who relied purely on local resources for her training. She stressed the need for trainers to actually experience the context in which their trainees work and the need to adapt their method to these settings. She emphasized the need for specialized training in both supervision work and in family therapy.

The plenary discussion took place after a second meeting of the small groups. It was unfortunate that some of the familiar polarization of 'those who have and those who have not' in relation to training facilities was not directed more to practical issues such as attracting London-based trainers to undertake short courses and supervision for the provinces, as it seems that there is more fluidity today.

More familiar issues such as research problems in psychotherapy were aired, as well as the interesting theme of 'psychic pain'. This latter being a point in discovering the amount of psychological depth that the clinician feels comfortable in his approach to his patient.

The dialogues continue and it is hoped that this meeting will become an annual event. 